$\xi=$

\title{
Analysis and cloning of CP 1102 gene isolated from a medicinal plant
}

\author{
Hira Mubeen ${ }^{1,2}$, Shahid Raza ${ }^{2}$ \\ ${ }^{1}$ National Institute for Biotechnology and Genetic Engineering, Faisalabad, Pakistan \\ ${ }^{2}$ Lahore Garrison University, Lahore, Pakistan \\ *Corresponding authorE-mail: hira_sh@hotmail.com
}

\begin{abstract}
Calotropis procera is a common medicinal plant with various properties related with its latex which functions as a rich source of biologically active compounds. Latex is chemically diverse and the chemical and biochemical differences are considerable for different plant fluids. This plant can produce large quantity of latex. The study was performed to clone the CP1102 terminator region of gene in general expression vector PTZ57R/T. The objective was to make a variant of pJITT166 (size $\sim 5.8 \mathrm{~kb}$ ) containing CP1102 terminator sequence to study different expression levels in future. The fragment of $341 \mathrm{bp}$ size was isolated. The pDNOR vector containing CP1102 terminator sequence was isolated and amplified by PCR. The forward and reverse primer specific to CP1102 terminator sequence which can amplify this sequence are designed by using bioinformatics tools.
\end{abstract}

Keywords: Pdnor; Latex; Terminator; Expression Vector.

\section{Introduction}

Calotropis procera is a tropical plant widely used in production of medicines. Calotropis procera is a spreading shrub or a $4 \mathrm{~m}$ small tree with grey-green flowers waxy white carried in stalked clusters at the ends of the branches 8 to $12 \mathrm{~cm}$ long, containing numerous seeds with tufts of long silky hairs at one end. This plant is commonly involved in production of large quantity of latex. However, medicinal plants are considered to be the major sources of traditional medicine worldwide (Goyal and Mathur, 2011).

Studies showed, C. procera plant latex has various therapeutic uses like anti-arthritic, anti-inflammatory, antipyretic and particularly for anticancer treatments (Shivkar and kumar, 2003: Dewan et al., 2000). These plants have been found to be very rich source of medicines because they produce wide array of bioactive molecules which acts as a chemical defense against certain infection (Shrivastav and Singh, 2013). However, it is estimated that only one percent of 2, 65, 000 flowering plants on earth have important characteristics to understand their chemical composition and medicinal value (Cox and Balick, 1994). All the parts of C. procera including root, stem, leaf and flowers are in common use for production of useful medicines (Mukherjee et al., 2010). C. procera latex is also considered to be an important source of secondary metabolites. From previous studies, latex was known to be chemically diverse with various biochemical differences. Also, it was observed about Hevea brasiliensis latex which is a rich source of poly isoprenes and an antifungal protein hevein (Oh et al., 2000: Van et al., 1991). Similarly, the Cardenolides in the C. procera latex are associated with toxic effects in mammals (Elgamal et al., 1999). In previous reports, insecticidal and antifungal proteins have been found. The need of time is to characterize the enzymatic profiles of all proteins (Frietas et al., 2014: Ramos et al., 2010).
The study was designed to analyze and clone the CP1102 terminator isolated from the medicinal plant in expression vector. For this, various molecular techniques have been used for cloning, elution, ligation of fragments and expression analysis. The methods used are described obtained below.

\section{Material and methods}

The CP1102 is a clone having one of the genes coded by C. procera. At the end of the gene there is a terminator sequence of $341 \mathrm{bp}$ size. A Terminator is a DNA sequence at the downstream region of gene that terminates the transcription of a gene. The objective was to make a variant of pJITT166 (size $\sim 5.8 \mathrm{~kb}$ ) containing CP1102 terminator sequence to analyze the expression of terminator in future. For this Purpose, the pDNOR vector containing CP1102 terminator sequence was isolated and amplified by PCR. The forward and reverse primers specific to CP1102 terminator sequence are used for amplification. EcoR1 and Xho1 restriction sties was found. The PCR product, CP1102 terminator sequence was then cloned into the PTZ57R/T vector. The size of pTZ57R/T is $2.8 \mathrm{~kb}$. The cloned PTZ57R/T and pJITT166 was then digested with EcoR1 and Xho1 and the two restricted mixtures were ligated to get CP1102 terminator sequence cloned in pJITT166. The clone CP1102 was streaked on LB media containing kanamycin and incubated it overnight. Bacteria was cultured in test tubes containing LB broth and incubated it overnight. Plasmids were isolated from culture by using alkaline lyses solutions and amplified by PCR. The reaction used for PCR is given in table 1 below: 
Table 1: Shows the PCR Reaction Mixture

\begin{tabular}{lll}
\multicolumn{3}{c}{ Table 1: Shows the PCR Reaction Mixture } \\
\hline PCR reagent & Concentration & Volume \\
\hline Genomic DNA $(1 \mu \mathrm{g} / \mu \mathrm{l})$ & $1: 40$ dilution & $5 \mu \mathrm{l}$ \\
dNTPs & $10 \mathrm{mM}$ & $1 \mu \mathrm{l}$ \\
Taq Buffer $(10 \mathrm{x})$ & $1 \mathrm{x}$ & $5 \mu \mathrm{l}$ \\
$\mathrm{MgCl}_{2}$ & $25 \mathrm{mM}$ & $4 \mu \mathrm{l}$ \\
Forward primer & $50 \mathrm{ng} / \mu \mathrm{l}$ & $1 \mu \mathrm{l}$ \\
Reverse primer & $50 \mathrm{ng} / \mu \mathrm{l}$ & $1 \mu \mathrm{l}$ \\
Taq Polymerase & $2.5 \mathrm{U}$ & $1 \mu \mathrm{l}$ \\
Double distilled $\mathrm{H}_{2} \mathrm{O}$ & & $32.0 \mu \mathrm{l}$ \\
Total Volume & & $50 \mu \mathrm{l}$ \\
\hline
\end{tabular}

The 20-25 $\mu$ l of amplified PCR product was loaded on gel. The $341 \mathrm{bp}$ band of CP1102 terminator sequence was eluted by using gel elution kit. Afterwards, the eluted DNA was ligated with $(\mathrm{PTZ} 57 \mathrm{R} / \mathrm{T})$ for TA cloning and incubated overnight at $16^{\circ} \mathrm{C}$. The ligation mixture was transformed into competent cells of E.coli DH10 strain and transformation mixture was spreaded on LB media containing X-gal and LPTG for blue white screening. The number of different white colonies were appeared. Plasmids was isolated from overnight cultures for screening of desired transfrmants by restriction digestion and PCR analysis. The recipe for restriction digestion $\mathrm{s}$ shown in table 2 below:

Table 2 :

\begin{tabular}{ll}
\hline REAGENTS & VOLUME $(\mu \mathrm{l})$ \\
\hline Plasmid DNA & $4 \mu 1$ \\
EcoRI & $1 \mu 1$ \\
Xhol & $1 \mu 1$ \\
Buffer Tango $(2 X)$ & $6 \mu 1$ \\
RNAse & $4 \mu 1$ \\
Water & $17 \mu 1$ \\
Total & $30 \mu 1$ \\
\hline
\end{tabular}

The cultures that contain clone pTZ57R/T with CP1102 terminator sequence was selected, streaked and then cultured for plasmid isolation by using Promega miniprep kit. The isolated plasmids were again digested with EcoR1 and Xho1 and further confirmed by PCR.

The phenol chloroform treatment was performed to restricted samples. In parallel the pJIT166 was also digested with same EcoR1 and Xho1 enzymes and restriction mixture of pJIT166 was treated with phenol chloroform treatment. The pJIT166 and clone pTZ57R/T with CP1102 terminator sequence was ligated and transformed into competent cells and spreaded on the LB media containing Ampicillin. The selected clones were cultured for plasmid isolation and screening of transformants. The isolated plasmids was again confirmed by PCR. The desired transformant containing pJIT166 with CP1102 terminator sequence, were then selected and was back streak for purified plasmid isolation. The plasmids were then confirmed by restriction digestion and PCR analysis. Glycerol stock of culture containing pJIT166 having CP1102 terminator sequence was made and stored for further analysis.

The ligation mixture was run on gel along with unligated eluted CP1102 and pTZ57R/T as shown in figure 2 below:

Ligated Unlighted

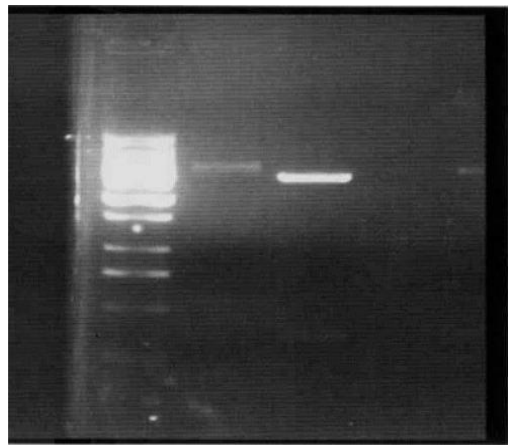

Fig. 2: Ligation Cp1102 (341bp) with PTZ57R/T and Unligated Cp1102 and PTZ57R/T.

\section{Results}

Several genes associated with CP1102 gene terminator was coded by $\mathrm{C}$. procera. Each gene has a terminator sequence at the $3^{\prime}$ end. The pDNOR plasmid with CP1102 terminator sequence of size $\sim 2.5 \mathrm{~kb}$ was isolated and subjected to PCR for getting amplified product of $341 \mathrm{bp}$. The reverse and forward primer were designed for the $341 \mathrm{bp}$ segment, which introduces specific restriction sites for EcoR1 and Xho1 into the terminator sequence. The PCR eluted fragment size was confirmed by gel electrophoresis. The advantage of this band elution is accuracy. But the strategy of elution was used for two reasons: first it is more accurate i.e. the ligation performed by eluting the desired fragments do not have probability of binding again into the pDNOR. Second it saves time to much a larger extent while transforming the ligation into the cells. After culturing cells screening of desired transformants was performed. Screening was performed till the time we get our desired fragments. Obtained results are shown below:

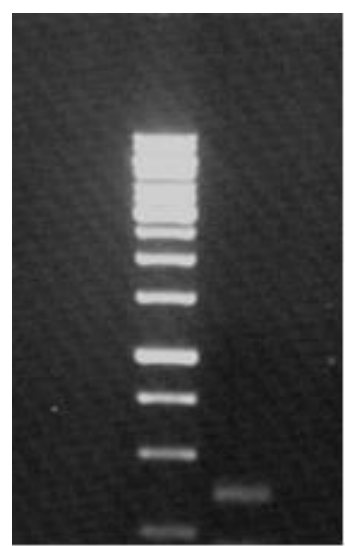

a)

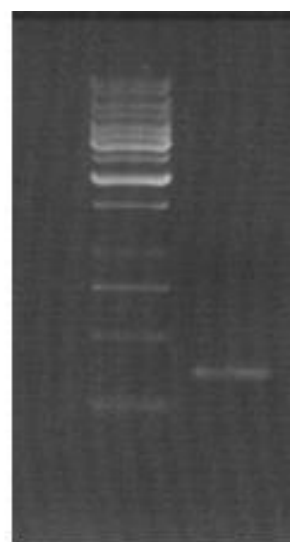

b)
Fig. 1: Shows A) PCR of CP1102 (341bp) B) Eluted Cp1102 (341bp).

The $341 \mathrm{bp}$ band confirmed that the CP1102 terminator sequence was eluted correctly. The eluted fragment of CP1102 terminator sequence was then ligated with TA cloning vector $\mathrm{pTZ57R/T}$. The size of $\mathrm{pTZ57R} / \mathrm{T}$ is $\sim 2.8 \mathrm{~kb}$ so the total size of $\mathrm{pTZ57R} / \mathrm{T}$ with CP1102 will become $\sim 3.1 \mathrm{~kb}$. The CP1102 terminator sequence was first cloned into pTZ57R/T vector because when we run PCR, adenine (A) is added at the end of the PCR product. While on the other hand pTZ57R/T has thiamine (T) residue at both ends. This presence of thiamin (T) and adenine (A) residues at the ends of pTZ57R/T and our PCR product of CP1102 respectively will facilitate in their ligation with each other. 
The ligated CP1102 and pTZ57R/T was then transformed and the transformation was spread on LB media plates containing IPTG and Xgal. As a result two types of colonies were obtained, blue colonies without insert, and white with CP1102 terminator inserted which is required. The white colonies were selected for culturing and plasmids were isolated the isolated plasmid are digested with EcoR1 and Xho1 and the restriction mixture is then run on gel for confirmation. Results are shown in figure 3 below:

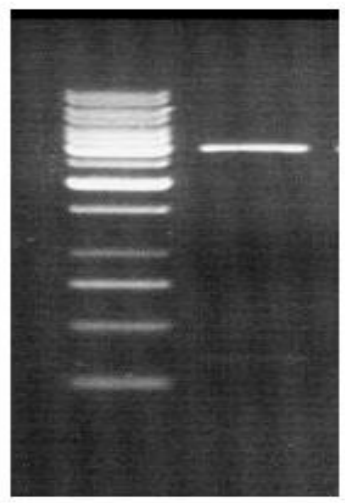

a)

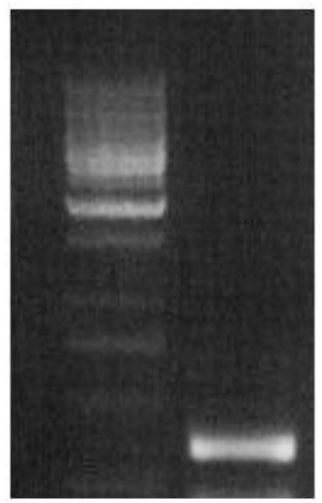

b)

Fig. 3: A) Restriction of CP1102 and PTZ57R/T B) PCR of Confirmed Clone CP1102 + PTZ57R/T.

The required restricted clone pTZ57R/T with CP1102 terminator sequence was treated with phenol chloroform treatment to purify the clone. The restricted phenol chloroform treated pJIT166 and CP1102 with pTZ57R/T were then ligated. Electrophoresis was carried out for ligation mixture containing pJITT166 and pTZ57R/T with CP1102. Results are shown in figure 4 below:

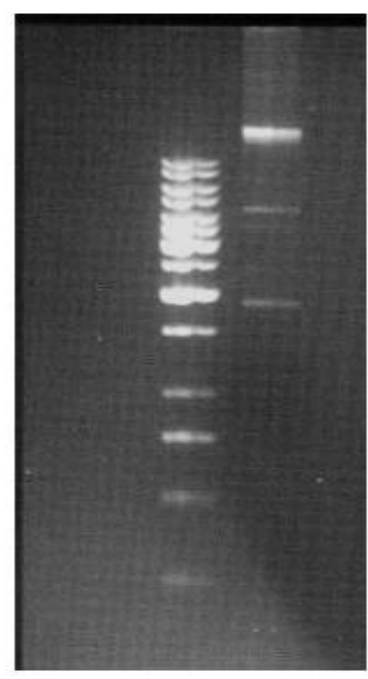

a)

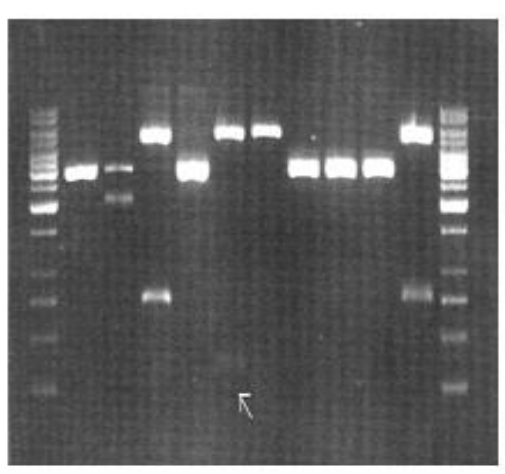

b)

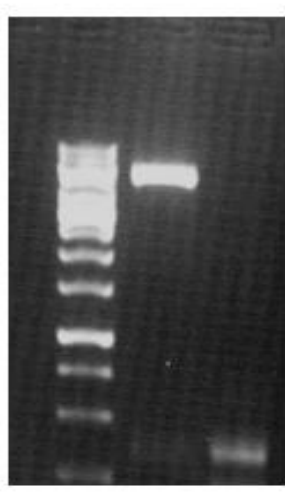

c)

Fig. 4: A) Ligation of Pjit166 (5kb) and CP1102 + Ptz57r/T) B) Restriction of Pjit166 (5kb) and CP1102 (341bp) C) PCR of Pjit166 (5kb) and CP1102 (341bp).

The culture containing clone pJIT166/cp1102 was then again streaked and cultured and the plasmid was isolated by using kit. Again the plasmid was confirmed by PCR and by Restriction with EcoR1 and Xho1 (fig 8).

\section{Discussion}

Calotropis procera has gain an important in medicine and industry It is a perennial shrub used for various applications including cheese making. It also plays an important role in first line of defense from pathogens. Calotropis procera belongs to family Asclepiadaceae and has been explored for different proteases. Previous studies showed various applications in food, dairy, detergent and several other industries. Calotropis procera plants have wavy leaves of bicular shape. The Calotropis procera leaves are light green and dark green with white veins [Abbas et al., 1992: Varshney and Bhoi, 1998). Calotropis procera has been characterized on the basis of its physical and chemical and properties, length and moisture absorption (Sakthivel et al., 2005). The analysis of
CP1102 revealed its importance for production of transgenic plants. Genetic modification of genes can result in various useful crops (Li et al., 2005: Pu et al., 2008). Some of the characteristic features indicated, CP1102 gene as an essential gene that can be used for various medicinal applications. Most importantly, CP1102 gene is important for improvement of crop strength and quality.

\section{Conclusion}

In this study, the Calotropis procera gene terminator (CP1102) was analyzed and cloned in cloning vector $\mathrm{pTZ} 57 \mathrm{R} / \mathrm{T}$. The fragment can be cloned in expression vector for further expression studies. Also, plant expression vector can be used for transgene analysis and to monitor expression through Histochemical GUS technique. The study revealed Calotropis procera genes can be used to increase quality and strength of crops. The genetic modification and engineering of crops can better provide scientific insight to conquer more ways of crop improvement. 


\section{Acknowledgement}

We are thankful to all colleagues for their kind support.

\section{References}

[1] Goyal, M., \& Mathur, R. (2011). Antimicrobial potential and phytochemical analysis of plant extracts of Calotropis procera. International journal of drug discovery and herbal research, 1(3), 138143.

[2] Shivkar, Y. M., \& Kumar, V. L. (2003). Anthelmintic activity of latex of Calotropis procera. Pharmaceutical biology, 41(4), 263265. http://dx.doi.org/10.1076/phbi.41.4.263.15666.

[3] Kumar, V. L., \& Basu, N. (1994). Anti-inflammatory activity of the latex of Calotropis procera. Journal of Ethnopharmacology, 44(2), 123-125. http://dx.doi.org/10.1016/0378-8741(94)90078-7.

[4] Kumar, V. L., \& Roy, S. (2007). Calotropis procera latex extract affords protection against inflammation and oxidative stress in Freund's complete adjuvant-induced monoarthritis in rats. Mediators of inflammation, 2007. http://dx.doi.org/10.1155/2007/47523.

[5] Choedon, T., Mathan, G., Kumar, V., Arya, S., \& Kumar, V. L. (2006). Citation of This Article. World J Gastroenterol, 12(16), 2517-2522. http://dx.doi.org/10.3748/wjg.v12.i16.2517.

[6] Dewan, S. O. N. E. E. R. A., Kumar, S. U. R. E. S. H., \& Kumar, V. L. (2000). Antipyretic effect of latex of Calotropis procera. Indian Journal of Pharmacology, 32(3), 252-252.

[7] Shrivastava, A., Singh, S., \& Singh, S. (2013). Phytochemical investigation of different plant parts of Calotropis procera. International Journal of Scientific and Research Publications, 3(3).

[8] Cox, P. A., \& Balick, M. J. (1994). The ethnobotanical approach to drug discovery. Scientific American (June), 60-65.

[9] Mukherjee, B., Bose, S., \& Dutta, S. K. (2010). Phytochemical and pharmacological investigation of fresh flower extract of Calotropis procera Linn. International Journal of Pharmaceutical Sciences and Research (IJPSR), 1(12), 182-187.

[10] Oh, S. K., Kang, H., Shin, D. H., Yang, J., \& Han, K. H. (2000). Molecular cloning and characterization of a functional cDNA clone encoding isopentenyl diphosphate isomerase from Hevea brasiliensis. Journal of plant physiology, 157(5), 549-557. http://dx.doi.org/10.1016/S0176-1617(00)80111-X

[11] Van Parijs, J., Broekaert, W. F., Goldstein, I. J., \& Peumans, W. J. (1991). Hevein: an antifungal protein from rubber-tree (Hevea brasiliensis) latex. Planta, 183(2), 258-264 http://dx.doi.org/10.1007/BF00197797.

[12] Elgamal, M. H. A., Hanna, A. G., Morsy, N. A., Duddeck, H., Simon, A., Gáti, T., \& Tóth, G. (1999). Complete 1H and 13C signal assignments of $5 \alpha$-cardenolides isolated from Calotropis procera $\mathrm{R}$ BR. Journal of molecular structure, 477(1), 201-208. http://dx.doi.org/10.1016/S0022-2860(98)00615-2.

[13] De Freitas, C. D. T., Nogueira, F. C. S., Vasconcelos, I. M. Oliveira, J. T. A., Domont, G. B., \& Ramos, M. V. (2011). Osmotin purified from the latex of Calotropis procera: biochemical characterization, biological activity and role in plant defense. Plant Physiology and Biochemistry, 49(7), 738-743. http://dx.doi.org/10.1016/j.plaphy.2011.01.027.

[14] Ramos, M. V., Grangeiro, T. B., Freire, E. A., Sales, M. P., Souza, D. P., Araújo, E. S., \& Freitas, C. D. (2010). The defensive role of latex in plants: detrimental effects on insects. Arthropod-Plant Interactions, 4(1), 57-67. http://dx.doi.org/10.1007/s11829-0109084-5.

[15] Abbas, B., El Tayeb, A. E., \& Sulleiman, Y. R. (1992). Calotropis procera: feed potential for arid zones. Veterinary Record, 131(6), 132-132. http://dx.doi.org/10.1136/vr.131.6.132-a

[16] Varshney, A. C., \& Bhoi, K. L. (1988). Cloth from bast fibre of the Calotropis procera (Aak) plant. Biological wastes, 26(3), 229-232. http://dx.doi.org/10.1016/0269-7483(88)90168-1.

[17] Sakthivel, J. C., Mukhopadhyay, S., \& Palanisamy, N. K. (2005) Some studies on Mudar fibers. Journal of industrial textiles, 35(1) 63-76. http://dx.doi.org/10.1177/1528083705053390.

[18] Li, X. B., Fan, X. P., Wang, X. L., Cai, L., \& Yang, W. C. (2005) The cotton ACTIN1 gene is functionally expressed in fibers and participates in fiber elongation. The Plant Cell, 17(3), 859-875. http://dx.doi.org/10.1105/tpc.104.029629.

[19] Pu, L., Li, Q., Fan, X., Yang, W., \& Xue, Y. (2008). The R2R3 MYB transcription factor GhMYB109 is required for cotton fiber development. $\quad$ Genetics, $\quad 180(2), \quad 811-820$ http://dx.doi.org/10.1534/genetics.108.093070.
[20] Wang, H. Y., Wang, J., Gao, P., Jiao, G. L., Zhao, P. M., Li, Y., \& Xia, G. X. (2009). Down-regulation of GhADF1 gene expression affects cotton fibre properties. Plant biotechnology journal, 7(1), 13-23. http://dx.doi.org/10.1111/j.1467-7652.2008.00367.x. 